\title{
Angelman syndrome with a chromosomal inversion 15 inv(p11q13) accompanied by a deletion in 15q11q13
}

\author{
T Webb, J Clayton-Smith, X-J Cheng, J H M Knoll, M Lalande, M E Pembrey, \\ S Malcolm
}

\begin{abstract}
A family is described in which an inversion of chromosome 15,15 inv(p11q13), is segregating. All family members are healthy except the proband who is a 10 year old boy with Angelman syndrome. Although the chromosomal inversion has been passed from the grandfather to both his son and his daughter with no ill effect, passage from daughter to grandson has resulted in a deletion of chromosome 15 material which is presumed to be the cause of Angelman syndrome in this boy. The probabilities of an inversion of this type being instrumental in causing the syndrome are discussed.

( $\mathcal{F}$ Med Genet 1992;29:921-24)
\end{abstract}

Angelman (AS) or happy puppet syndrome ${ }^{1}$ is characterised by mental retardation, jerky movements, and lack of speech, often accompanied by a happy disposition with bouts of uncontrolled laughter and tongue thrusting. The syndrome can often be differentiated by a characteristic electroencephalogram (EEG). ${ }^{2}$

High resolution cytogenetic studies have

Department of Clinical Genetics, University of Birmingham, Birmingham Maternity Hospital, Edgbaston, Birmingham B15 2TG.

T Webb

Institute of Child Health, 30 Guilford Street, London WC1N 1EH.

J Clayton-Smith

X-J Cheng

M E Pembrey

S Malcolm

Genetics Division, Children's Hospital, 300 Longwood Avenue, Boston, MA 02115, USA.

J H M Knoll

M Lalande

Correspondence to Dr Webb.

Received 19 February 1992. Revised version accepted 15 May 1992. pairs of sibs with Angelman syndrome have been described and the recurrence risk may be syndromes but also the distinct parental origin of each. ${ }^{9-12}$

Prader-Willi syndrome has occasionally been reported to recur within a family, ${ }^{1314}$ but the risk is generally considered to be very low much higher than for PWS. Although it does not approach the $25 \%$ which would be expected for an autosomal recessive mode of inheritance, it may be in the region of $4 \% .^{16}$

Although two pericentric inversions of chromosome 15 have been associated with PWS, ${ }^{17} 18$ one, which had the karyotype 46,XY, inv(15) (p13q13), was also present in the child's healthy father. In another case both the patient's father and grandmother carried a pericentric inversion with breakpoints in p11 and q12. ${ }^{18}$ Cytogenetic rearrangements involving proximal $15 \mathrm{q}$ had not previously been described in AS, until the finding of a pericentric inversion $\operatorname{inv}(15)$ (p11q13) in a boy with Angelman syndrome and in his normal mother. ${ }^{4}$ This prompted detailed investigations involving cytogenetic and molecular analysis of all available family members in order to attempt to clarify the relationship between the chromosomal abnormality and the syndrome and to aid in the elucidation of the aetiology of the disease.

\section{Methods}

CASE REPORT

The proband is a 10 year old boy who was born after a normal delivery to a 24 year old mother and a 26 year old father. His birth weight was $2850 \mathrm{~g}$ and there was concern about his development from birth because of severe feeding problems. He smiled at 6 weeks and sat at 10 months, but never crawled and began to walk at the age of 4 years with an ataxic, wide based gait. He had his first seizure at the age of 2 years and the diagnosis of AS was made at 5 years of age because of his clinical characteristics and EEG abnormalities.

On examination at the age of 10 years he had brachycephaly with an occipitofrontal circumference between the 25 th and 50 th centiles. He has blue eyes and blonde hair and has no speech but can communicate in a limited fashion using sign language. $\mathrm{He}$ is markedly ataxic but has had no seizures for three years. $\mathrm{He}$ is a happy child who laughs with minimal provocation.

The proband has two younger sibs who are both intellectually normal. His mother is of normal intellect with blonde hair and blue eyes 

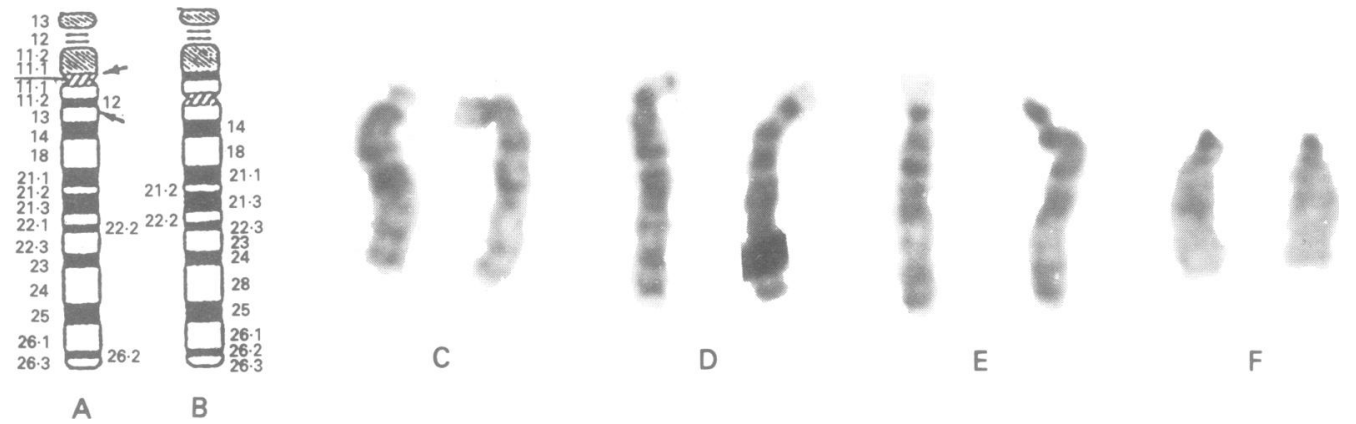

Figure 1 Ideograms of chromosome 15 and partial karyotypes. (A) Ideogram of chromosome 15 (ISCN 1985), (B) ideogram showing 15 inv (p11q13). Giemsa banded chromosomes 15 from (C) the grandfather $1.1,(D)$ his daughter II.2, and $(E, F)$ his grandson III.1. Chromosome pair $(F)$ on the extreme right shows Ag staining of the $N O R$ region. In each case the abnormal chromosome is on the right hand side of the pair. Arrows indicate breakpoints.

and his father, who has dark hair and brown eyes, is of above average intelligence. The proband has two maternal uncles and two maternal cousins, all of whom are phenotypically normal, as are his maternal grandparents.

\section{CYTOGENETICS}

Lymphocytes from each member of the family were subjected to a series of culture methods designed to facilitate high resolution cytogenetics at the 850 band level. These included synchronising of division with an excess of thymidine followed by release for different periods of time and intercalating the chromosomes with ethidium bromide. Harvesting of the cultures, slide making, GTG banding, and silver staining of nucleolar organiser regions (NOR) were all by standard methods.

MOLECULAR STUDIES

Probes and polymorphisms

DNA probes ${ }^{19}$ IR10-1 (D15S12), pML34

(D15S9), pTD 189-1 (D15S13), pTD 3-21

(D15S10), and IR4-3R (D15S11) were used for RFLP analysis. ${ }^{20}$ Polymorphic alleles were shown by $S c a I$ in the first two cases, TaqI in the second two, and $R s a I$ in the last. In addition, the CA repeat associated with probe $\mathrm{pTD}$ 3-21 (D15S10) and the VNTR probe CMW-1 (D15S24), which lies just proximal to the chromosomal region which is believed to contain the AS gene, were also used to track chromosomes 15 segregating in this family. The $(\mathrm{CA})_{\mathrm{n}}$ dinucleotide polymorphism within D15S10 was detected as described previously. ${ }^{21}$

\section{Restriction enzyme analysis}

DNA was extracted from blood collected into EDTA tubes by guanidinium hydrochloride and proteinase $\mathrm{K}$ extraction. ${ }^{22}$ For RFLP analyses agarose gels were run in standard fashion and after denaturation the DNA was blotted directly in alkali onto Hybond $\mathrm{N}+$. The DNA probes were radiolabelled using random hexanucleotide priming. After hybridisation the filters were washed in $3 \times$ SSC, $0.1 \%$ SDS at room temperature for one hour and $1 \times \mathrm{SSC}$, $0.1 \%$ SDS at $65^{\circ} \mathrm{C}$ for 20 minutes, and exposed using Kodak XOMAT film. Quantitative hybridisations were performed as described previously. ${ }^{1123}$

\section{Results \\ CYTOGENETICS}

Partial karyotypes from the family are shown in fig 1 and the pedigree in fig 2 . The proband, III.1, has an inversion of chromosome 15 with breakpoints in $15 \mathrm{p} 11$ and $15 \mathrm{q} 12 \mathrm{q} 13$. This inverted chromosome 15 is also present in his normal mother, II.2, his maternal grandfather, I.1, and his maternal uncle. Other family members have normal karyotypes. III.1 is the only member of the family who has Angelman syndrome. Polymorphisms of the satellites present on the short arms of chromosome 15 indicate that II.2 and her brother have inherited different normal homologues from their mother who has one chromosome 15 with satellites and one without. II.2 has inherited the satellited homologue and her brother the non-satellited. The position of the NOR region in the inverted chromosome 15 is unchanged as shown by silver staining.

\section{MOLECULAR STUDIES}

The family was studied using a series of molecular probes which show polymorphisms at loci D15S9-D15S13 (lying within the chromosomal region of interest) with the VTNR probe CMW-1 detecting locus D15S24 which is situated just distal to the segment believed to contain the AS and PWS genes, and with a (CA) $n$ repeat lying within the region of interest. The deduced haplotypes are shown in fig 2 .

Dosage studies have indicated that III.1 has a de novo deletion of the PWCR which includes loci D15S9, D15S10, D15S11, $D 15 S 12$, and $D 15 S 13$ (fig 2). He is, however, heterozygous at locus D15S24 which is detected by probe CMW-1.

\section{Discussion}

A boy has been identified with Angelman syndrome and a familial pericentric inversion of chromosome 15, inv(15p11q13). Three other family members, including the boy's mother, who also carry the inversion are 
I

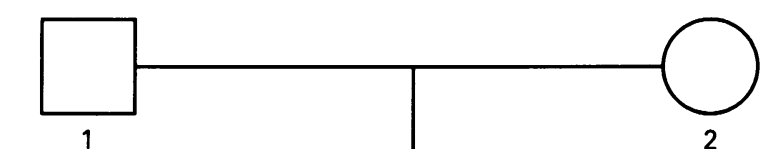

\begin{tabular}{lll} 
Locus & \multicolumn{2}{c}{ Alleles } \\
D15S13 & - & - \\
$D 15 S 9$ & a & a \\
D15S11 & a & a \\
$D 15 S 10$ & 2 & 2 \\
$D 15 S 12$ & b & b \\
D15S24 & a & a \\
& & inv
\end{tabular}

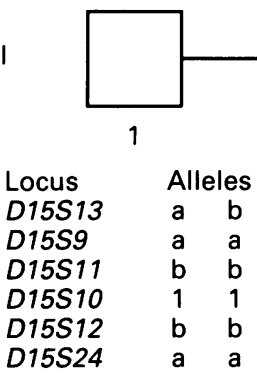

III

$\begin{array}{cc}\text { Alleles } \\ \text { a } & \Delta \\ \text { a } & \Delta \\ \text { b } & \Delta \\ 1 & \Delta \\ \text { b } & \Delta \\ \text { a } & \text { b } \\ & \text { inv }\end{array}$

Figure 2 Inheritance patterns in family of loci situated in the 15q11-q13 region. All probes corresponding to the loci listed are given in the text. The order is that determined by Nicholls et al. ${ }^{20}$ contraindicate a disruption of any contiguous gene segment responsible for both PWS and AS, thus suggesting that the critical regions of the two disorders may be distinct. ${ }^{24} 25$

(3) Interstitial duplications and deletions are facilitated by unequal crossing over which can occur in association with chromosome inversions. ${ }^{26}$ Owing to the pericentric inversion inv(15p11q13) present in one homologue, the chromosome 15 in the patient's mother, II.2, failed to pair correctly at meiosis and an incompletely matched crossover caused a de novo deletion in 15q12 which could explain the presence of Angelman syndrome in her son.

Pericentric inversions occur when the chromosome suffers two breaks, one on either side of the centromere. The segment between the breaks turns through $180^{\circ}$ before rejoining. The result is a balanced rearrangement but some material is exchanged between the short and long arms of the chromosome. Misalignment at meiosis followed by a crossover increases the risk of imbalance in offspring leading to trisomy or monosomy for the segments of the chromosome involved. In this boy, III.1, a deletion of part of the region situated at $15 \mathrm{q} 12$ could be the outcome of such a crossover. The spacing of the GTG bands in the inverted chromosome 15 present in II. 2 indicates that the break in the long arm is most likely to have occurred near to the $15 \mathrm{q} 12$ $15 \mathrm{q} 13$ interface which would move bands 15q11-2 above the centrometre and into the short arm (fig 1). As the area encompassing Angelman syndrome is believed to be within this region, if recombination does occur then looping out leading to unequal crossing over in association with it is very likely.

The deletion in III.1 is believed to be of maternal origin because of the large numbers of crossovers which must be postulated if it was paternally derived and to have arisen de novo because his mother, II.2, is heterozygous at three loci for which he is deleted (D15S10, $D 15 S 11$, and D15S13). The phase of all probes on the inverted chromosome 15 is known in II.1, as her father, I.1, is homozygous for all probes tested. III.1 carries the inversion on the chromosome 15 inherited from his mother but is deleted for D15S9, D15S10, D15S11, D15S12, and D15S13. He is heterozygous, and so not deleted, at D15S24 (CMW-1). His father is homozygous aa for D15S24 and, as he is ab, the b allele must have come from his mother and originally from his grandmother. Thus, the deletion starts proximally on the chromosome of II.1 inherited from her father (I.1), but there is a recombination with the chromosome derived originally from I.2. This is confirmed by the presence in the deleted/recombined chromosome of the $b$ allele of D15S24. The crossover at meiosis presumably facilitated the deletion.

Angelman syndrome is associated with de novo deletions occurring in apparently normal homologues of chromosome 15 and with uniparental disomy. Familial rearrangement of the $15 \mathrm{p} 11 \mathrm{q} 13$ region may also predispose to the syndrome. In this family an inversion the hypothesis of imprinting neither would be expected to have Angelman syndrome. Neither, however, has PWS which would 
involving breakpoints at $15 \mathrm{p} 11$ and $15 \mathrm{q} 13$ has been passed from a grandfather (I.1) to two of his children with no apparent deleterious effect, but when his daughter (II.2) passed the inverted chromosome on to her son, a deletion occurred and Angelman syndrome resulted. The region is prone to chromosomal rearrangements such as de novo deletions, unbalanced translocations, inversions, and duplications. Although the recurrence of Angelman syndrome within a sibship does not appear to be associated with a cytogenetic deletion of chromosome 15 , the presence of a familial chromosomal abnormality such as the one present in this family may increase the risk substantially, so counselling should be approached with caution.

A cell line has been stored from the proband. (Contact Dr Sue Malcolm, Institute of Child Health, 30 Guilford Street, London WC1N 1EH.)

JCS is an Action Research training fellow and XJC a WHO training fellow. We gratefully acknowledge financial support from Action Research and WHO.

1 Angelman H. 'Puppet' children: a report on three cases. Dev Med Child Neurol 1965;7:681-8.

2 Boyd SG, Harden A, Patton MA. The EEG in early diagnosis of the Angelman (happy puppet) syndrome. Eur f Pediatr 1988;147:508-13.

3 Kaplan LC, Wharton R, Elias E, Mandell F, Donlon T, aplan LC, Wharton R, Elias E, Mandell F, Donlon T, in the long arm of chromosome 15: report of 3 new cases and their possible genetic significance. Am $\mathcal{f}$ Med Genet and their possible

4 Pembrey M, Fennell SJ, Van den Berghe J, et al. The association of Angelman's syndrome with deletions within 15q11-13. F Med Genet 1989;26:73-7.

5 Ledbetter DH, Mascarello JT, Riccardi VM, Harper VD, Airhart DS, Strobel RJ. Chromosome 15 abnormalities and the Prader-Willi syndrome: a follow-up report of 40 cases. Am ₹ Hum Genet 1982;34:278-85.

6 Ledbetter DH, Riccardi VM, Airhart SD, Strobel RJ, Kennan BS, Crawford JD. Deletions of chromosome 15 as a cause of the Prader-Willi syndrome. $N$ Engl $7 \mathrm{Med}$ 1981;304:325-9.

7 Knoll JHM, Nicholls RD, Magenis RE, Graham JM, Lalande M, Latt SA. Angelman and Prader-Willi synLalande M, Latt SA. Angelman and Prader-Will syndromes share a common chromosome deletion but differ in parental origin
8 Butler MG, Palmer CG. Parental origin of chromosome 15 deletion in Prader-Willi syndrome. Lancet 1983;i:1285-6. deletion in Prader-Willi syndrome. Lancet 1983;i:1285-6.
Magenis RE, Toth-Fejel S, Allen J, et al. Comparison of the Magenis RE, Toth-Fejel S, Allen J, et al. Comparison of the
15q deletions, in Prader-Willi and Angelman syndromes. Am $\mathcal{f}$ Med Genet 1990;35:333-49.

10 Williams CA, Zori RT, Stone JW, Gray BA, Cantu ES Ostrer $\mathrm{H}$. Maternal origin of 15q11-13 deletions in Angelman syndrome suggests a role for genomic imprinting. Am f Med Genet 1990;35:350-3.

11 Knoll JHM, Nicholls RD, Magenis RE, et al. Angelman syndrome. Three molecular classes identified with chromosome 15q11 q13 specific DNA markers. Am $\mathrm{f} \mathrm{Hum}$ Genet 1990;47:149-55.

12 Clayton-Smith J, Webb $T$, Pembrey $M E$, Nichols $M$ Malcolm S. Maternal origin of deletion 15q11-13 in 25/25 cases of Angelman syndrome. Hum Genet 1992;88:376-8.

13 Lubinsky M, Zellweger H, Greenswag L, Larson G Hansmann I, Ledbetter D. Familial Prader-Will syndrome with apparently normal chromosomes. $A m \mathcal{F}$ Med Genet 1987;28:37-43.

14 Ishikawa $T$, Kanayama $M$, Wada Y. Prader-Willi syndrome in two siblings: one with normal karyotype, one with terminal deletion of distal Xq. Clin Genet 1987;32:295-9.

15 Cassidy SB. Recurrence risk in Prader-Willi syndrome. $A m$ f Med Genet 1987;28:59-60.

16 Willems PJ, Dijkotra J, Brouwer OF, Smit GPA. Recurrence risk in the Angelman ('happy puppet') syndrome. rence risk in the Angelman ('happy

17 Winsor EJT, Welch JP. Prader-Willi syndrome associated with inversion of chromosome 15. Clin Genet 1983; 24:456-61.

18 Kahkonen $M$, Kokkonen HL, Haapala $\mathrm{K}$, Winquist $\mathbf{R}$ Leisti J. Discrepancy in cytogenetic and DNA analyses of a patient with a deletion of proximal $15 q$ due to familial pericentric inversion and analysis of eight other patients diagnosed to have Prader-Willi syndrome. Am f Hum Genet 1990;47:31A

19 Donlon TA, Lalande M, Wyman A, Bruns G, Latt SA Isolation of molecular probes associated with the chromosome 15 instability in the Prader-Willi syndrome. Proc Natl Acad Sci USA 1986;83:4408-12.

20 Nicholls RD, Knoll JH, Glatt K, et al. Restriction fragment length polymorphisms within proximal $15 \mathrm{q}$ and their use in molecular cytogenetics and the Prader-Willi syndrome. Am $\mathcal{F}$ Med Genet 1989;33:66-77

21 Lindeman RJ, Kouts S, Woodage T, Smith A, Trent RJ. Dinucleotide repeat polymorphism of D15S10 in the Prader-Willi chromosome region (PWCR). Nucleic Acids Res 1991;19:5449.

22 Jeanpierre $M$. A rapid method for the purification of DNA from blood. Nucleic Acids Res 1987;15:9611.

23 Tantravahi U, Nicholls RD, Stroh $\mathrm{H}$, et al. Quantitative calibration and use of DNA probes for investigating calibration and use of DNA probes for investigating Am $\mathcal{F}$ Med Genet 1989;33:78-87.

24 Wagstaff J, Knoll JHM, Fleming J, et al. Localisation of the gene encoding the GABA receptor B3 subunit to the Angelman/Prader-Willi region of human chromosome 15 Am $\mathcal{F}$ Hum Genet 1991;49:330-7.

25 Hamabe J, Fukushima Y, Harada N, et al. Molecular study of Prader-Willi syndrome: deletion, RFLP, and phenotype analysis of 50 patients. Am F Med Genet 1991;41:54 63.

26 Hoo JJ. Interstitial duplication/deletion owing to unequal crossing over in association with pericentric inversion. $f$ Med Genet 1983;20:234-5. 